\title{
NEWS AND REVIEWS
}

\section{Commonwealth Journal of Local Governance}

Issue 2: January 2009

http://epress.lib.uts.edu.au/ojs/index.php/cjlg

\section{Randal Smith}

London Borough of Hackney, UK

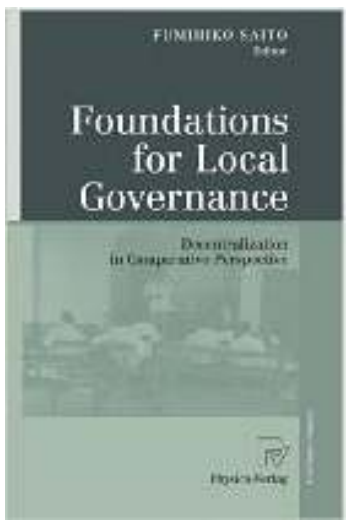

Foundations for Local Governance: Decentralization in Comparative Perspective

Fumihaiko Saito (Physica-Verlag, Heidelberg, 2008)

This is a rich collection of case studies and will be valuable to anyone seeking a wide range of examples of local governance and decentralisation in developing countries. It covers Indonesia, India (Kerala and Karnataka), Sri Lanka, Uganda, South Africa and Ghana. With the exception of Sri Lanka, all the countries have two chapters devoted to them by different authors, thus providing a broader perspective on both the context of decentralisation and research findings.

It is also interesting to have the perspectives of different national outlooks and disciplines - anthropologists, scholars of public administration, geographers, economists and political scientists.

However the studies are of variable quality. It is a major editing challenge to bring together such varied perspectives to produce a coherent publication, and that has not been fully achieved in this instance. Many of the chapters would have benefited from rigorous sub-editing to reach an evenness of international English. This may have resulted in the loss of distinctive voices, but it would have improved the readability of the book as a whole.

In the introduction, Saito seeks to bring a binding theme to the whole book. However, there are many generalisations and over-extended assertions lacking evidence or substantiation. At one point he asserts: "In the context of developing countries, the decentralized state is considered ideal to help reduce pervasive poverty. The world today is following the Millennium Development Goals (MDGs), which was [sic] adopted by the United Nations General Assembly in 2000." Who considers the decentralized state ideal? Few countries devolve sufficient finance for local governance to be truly successful, and few allow even a measure of autonomy over the finances. 
Whether intentional or not, Saito appears to adopt an extremely managerialist line in the introduction, for example asserting the view that the requirement placed on UK local government to work in partnership with local public private and voluntary sector bodies is a process fraught with tension. But the real point here is that local government is expected to provide strategic leadership for the area, manage the tensions, and make the delivery of key outcomes more likely and more efficient in doing so. This is not a 'process' in the management sense: it is a series of political challenges and responses.

In most cases the two chapters on each country are split between a substantial description of the local government system in one, followed by an analytical chapter. The descriptive chapters are excellent and very useful: basic descriptions of local government systems are hard to find and their contribution should not be overlooked.

The chapters on Indonesia are fascinating, but frustratingly ahistorical. At one point Tikson writes that: "Outside Java, the administration reforms that took place in the 1930s were actually made to accommodate the existence of traditional laws." Without going into the issue of the origins and validity of the so-called traditional laws, why should this be of any surprise? This was an administrative reform driven by the metropolitan power to make colonial rule more efficient - indirect rule through traditional leaders was simply cheaper. At around this time a similar approach to indirect rule was being applied across British Africa, and there was much interaction on the administration of indigenous peoples between the Dutch and British in this period.

The chapters on India are excellent - both sharply focused on the core issues and yet providing the reader with a strong sense of the external and internal pressures for change. Writing on Kerala, Harilal notes the tensions between state and local government, arguing that the relationships need restructuring.

The analytical chapters on Uganda, South Africa and Ghana all bring out the tensions that exist in those systems, and should be put to good use by those interested in local government and development. It is often the case that local government cannot drive development, but that it can help remove some of the barriers to development, and so it is important to have lucid analyses of the systemic tensions - tensions to which practitioners are often blind. 